\title{
Twin pregnancies: incidence and outcomes in a tertiary health centre of Uttarakhand, India
}

\section{Purnima Upreti*}

Department of Obstetrics and Gynaecology, Haldwani Government Medical College, Haldwani, Uttarakhand, India

Received: 18 July 2018

Accepted: 23 July 2018

\section{*Correspondence:}

Dr. Purnima Upreti,

E-mail: purnima_upreti@yahoo.com

Copyright: (C) the author(s), publisher and licensee Medip Academy. This is an open-access article distributed under the terms of the Creative Commons Attribution Non-Commercial License, which permits unrestricted non-commercial use, distribution, and reproduction in any medium, provided the original work is properly cited.

\begin{abstract}
Background: The frequency of twin pregnancies varies among different regions, countries and populations mostly due to the variation in dizygotic twinning. Twin pregnancy is associated with adverse maternal and fetal outcomes. This study was aimed to find out the frequency and outcome of twin pregnancies in a tertiary health centre of Uttarakhand.

Methods: This is a retrospective hospital record-based study of the twin deliveries (with gestational age of 28 weeks and above) which took place in a tertiary health care centre of Uttarakhand from January 2016 to December 2017. Data regarding age, parity and registration status of women who delivered twins, factors associated with twin pregnancy, gestational age, fetal presentation, mode of delivery, pregnancy complications and neonatal outcome was collected and analyzed.

Results: The frequency of twin pregnancy was found to be 1 in 52 pregnancies or $1.9 \%$. Majority (56.4\%) of the participants were in the age group of 21-25 years. 52.8\% were multipara. $74.3 \%$ were unbooked. $3.7 \%$ conceived after ovulation induction and $8.2 \%$ had family history of twins. Pre-term labour $(58.3 \%)$ was the most common complication followed by malpresentation (around 37\%). Cephalic-cephalic was the commonest fetal presentation (43.8\%).58.3\% neonates were premature at birth and $83.4 \%$ had low birth weight. Male-male was the commonest sex combination of twin pair $(30.4 \%)$ followed by female-female $(28.6 \%)$.

Conclusions: Twin pregnancy is a high-risk pregnancy associated with adverse maternal and fetal outcomes.
\end{abstract}

Keywords: Low birth weight, Malpresentation, Preterm labour, Twin pregnancy

\section{INTRODUCTION}

The incidence of multiple pregnancies varies significantly among different regions, countries and populations. In several overview studies (since the early 1970) it was found that natural twinning rates were less than 8 twin births per 1000 births in East Asia and Oceania, 9-16 per 1000 births in Europe, USA and India and 17 and more per1000 births in African countries. ${ }^{1-5}$ Smith et al reported that India has twining rates below 9 per 1000 births. ${ }^{6}$ Differences in twining rates among countries are mainly due to variations in the frequencies of dizygotic twinning. Rate of monozygotic twining is relatively constant (3.5-4 per 1000 births). ${ }^{1}$ Monozygotic twinning has no correlation with maternal age, race, parity and heredity.

However, dizygotic twinning is affected by maternal age, maternal height, race, parity, heredity, smoking habit, use of oral contraceptives and use of assisted reproductive techniques (ART). ${ }^{7-9}$

The incidence of twin pregnancy has been showing a rising trend attributable to increasing use of assisted reproductive techniques and increasing number of women having pregnancy at advanced age. In India, the incidence 
of twinning has increased marginally in last fourteen years (Not more than 0.84 per 1000 births). ${ }^{10}$

Twin pregnancy is associated with variety of maternal and fetal complications.

Common maternal complications reported in various studies are nutritional anemia, pregnancy induced hypertension, antepartum hemorrhage, polyhydramnios, preterm labour and postpartum haemorrhage. Twins are more susceptible than singletons. They have lower birth weight and are often premature. They have higher risk of fetal and neonatal morbidity and mortality.

Considering the different incidence of twin pregnancies and their complications reported in different studies, this study was aimed to find out the incidence of twin pregnancies and their maternal and fetal outcomes in a tertiary healthcare centre of Uttarakhand.

\section{METHODS}

\section{Study Design}

This retrospective descriptive study was conducted in the Department of Obstetrics and Gynaecology of a tertiary health care centre of Haldwani in the Nainital district of Uttarakhand state, India, over a period of two-years from January 2016 to December 2017.

\section{Inclusion Criteria}

Pregnant Women who delivered twins at or after 28 weeks of gestation at our institute, during the stipulated study period.

\section{Exclusion Criteria}

Women with twin pregnancy, delivering at gestational age $<28$ weeks.

\section{Data Collection and Analysis}

The hospital medical records of the stipulated study period were analysed to collect data of the study subjects. A predesigned format was used to record data pertaining to maternal characteristics, such as maternal age, parity (primiparous vs. multiparous), registration status (booked/unbooked) nature of conception (natural/induced) and family history of twins, gestational age at the time of delivery (weeks), fetal presentation(cephalic/Other than cephalic), mode of delivery (vaginal vs. caesarean), maternal medical complications, which included anemia, preeclampsia, eclampsia, obstetrical complications such as antepartum haemorrhage, premature rupture of membranes, pre term delivery, fetal distress, cord prolapse, retention of second twin, post-partum haemorrhage, nature of birth (live birth/ still birth), sex, APGAR score at birth and birth weight of neonates. The collected data was entered in MS excel sheet and analyzed using SPSS version 17. Results were expressed as frequencies, percentages, and mean \pm standard deviation (SD)

\section{Definition}

- $\quad$ Booked was defined as pregnant woman who had at least 3 antenatal visits.

- Gestational age was based on the number of days between the first day of an expectant mothers' last menstrual period (LMP) and date of delivery and was expressed in completed weeks after the LMP.

- Anemia was defined by hemoglobin levels <10 gram $\%$ during pregnancy.

- Pre- eclampsia was defined as BP of 140/90 mm of $\mathrm{Hg}$ or more with proteinuria during pregnancy

- Eclampsia was defined as pre-eclampsia with convulsions with or without coma.

- Malpresentation was defined as fetal presentation other than cephalic.

- Premature rupture of membranes was defined as rupture of membranes before the onset of labour

- Pre-term labour was defined as onset of labour before 37 completed weeks of gestation

- $\quad$ Pre-term delivery was defined as delivery before 37 completed weeks of gestation

- Low birth weight was defined as birth weight $<2500$ grams.

- Low APGAR score was defined as scores of $<7$ at one minute and five minutes after birth.

\section{RESULTS}

There were 11,443 deliveries during the study period. Out of them, 218 were twin deliveries. The incidence of twin pregnancy was found to be 1 in 52 pregnancies or $1.9 \%$ or 19 per 1000 births.

Table 1 shows the characteristics of mothers who delivered twins.

Maximum number of women belonged to age group of 21-25 years $(56.4 \%)$. The mean maternal age was 25.4years. $52.8 \%$ of women were multipara. Most of them $(74.3 \%)$ had less than 3 antenatal visits. $96.3 \%$ women had spontaneous conception. However, $3.7 \%$ women conceived after ovulation induction. Family history of twins was found in $8.2 \%$ of women.

The mean gestational age at delivery was found to be 35.2 weeks (Table 1).

In present study, pre-term labour resulting into preterm delivery was found to be the most common complication of twin pregnancy. 58, 3\% of women delivered before 37 completed weeks of gestation (Table 2). Fetal malpresentation was found in $37.2 \%$ of the first delivered twins and $37.6 \%$ of the second delivered twins in present study (Table 2). Maternal anaemia was the commonest 
medical complication $(30.7 \%)$ in present study. Preeclampsia was found in $17.9 \%$ of our cases. Other obstetric complications included ante partum haemorrhage $(5.9 \%)$, polyhydramnios $(5.5 \%)$, pre-mature rupture of membranes $(4.1 \%)$, fetal distress $(4.1 \%)$ and post-partum haemorrhage $(4.1 \%)$. There was retention of second twin in $2(0.9 \%)$ cases (Table 2$)$.

Table 1: Distribution of mothers according to selected variables.

\begin{tabular}{|lll|}
\hline Variables & $\begin{array}{l}\text { No. } \\
(\mathbf{n = 2 1 8})\end{array}$ & $\%$ \\
\hline Maternal age (Years) & & \\
\hline$<20$ & 01 & 00.4 \\
\hline $20-25$ & 123 & 56.4 \\
\hline $25-30$ & 68 & 31.2 \\
\hline $30-35$ & 19 & 08.7 \\
\hline$>35$ & 07 & 03.2 \\
\hline Mean maternal age (SD) & $25.4 \pm(4.40)$ & \\
\hline Parity & & \\
\hline Primipara & 103 & 47.2 \\
\hline Multipara & 115 & 52.8 \\
\hline Registration status & & \\
\hline Unbooked & 162 & 74.3 \\
\hline Booked & 056 & 25.7 \\
\hline Family history of twins & & \\
\hline Yes & 18 & 08.2 \\
\hline No & 200 & 91.7 \\
\hline Conception & & \\
\hline Spontaneous & 210 & 96.3 \\
\hline Induced & 08 & 03.7 \\
\hline Gestational age at delivery (weeks & \\
\hline$<34$ & 47 & 21.6 \\
\hline$\geq 34-<37$ & 80 & \\
\hline$\geq 37$ & 91 & \\
\hline $\begin{array}{l}\text { Mean gestational age at } \\
\text { delivery (SD) }\end{array}$ & $35.2 \pm(2.60)$ & \\
\hline & & \\
\hline
\end{tabular}

There was one case of fetus papyraceous (second twin) with the crown rump length of $8 \mathrm{~cm}$ and weight 150 grams.

In present study, Cephalic-cephalic was the commonest presentation $(43.8 \%)$ followed by cephalic -breech and breech -cephalic (17.9\% each). Transverse-cephalic was the least common presentation. $(0.9 \%)$ (Table 3$)$.

$51.2 \%$ of first twins and $50.5 \%$ of second twins delivered vaginally. Caesarean delivery rate was higher for second twins as compared to first $(49.5 \%$ vs $48.6 \%$ ) (Table 4$)$. Two cases presented with retention of second twin requiring caesarean section.

The average interval between delivery of the first and second twin was 9.2 minutes, the longest being 242 minutes. In present study, 92.6\% neonates were born alive. Low birth weight was found to be the most common neonatal complication followed by prematurity. $83.4 \%$ of live born neonates had low birth weight whereas $58.3 \%$ were premature at birth. $10.7 \%$ of live born neonates had low APGAR score at birth (Table 5).

Out of 32 stillborn twins, 12 were first born twins and 20 second born twins. There were six pairs of twins who died in utero. Out of remaining 20 stillbirths, 6 were first twins ( 4 died in utero and 2 fresh stillbirths) and 14 were second twins, (9 died in utero and 5 fresh still births).

Table 2: Pregnancy complications.

\begin{tabular}{|lll|}
\hline Pregnancy complications & No $(\mathbf{n}=218)$ & $\%$ \\
\hline Pre-eclampsia & 39 & 17.9 \\
\hline Eclampsia & 07 & 3.2 \\
\hline Anaemia & 67 & 30.7 \\
\hline Ante partum haemorrhage & 13 & 5.9 \\
\hline Polyhydramnios & 12 & 5.5 \\
\hline Malpresentation & & \\
\hline First twin & 81 & 37.2 \\
\hline Second twin & 82 & 37.6 \\
\hline Preterm delivery & 127 & 58.3 \\
\hline Pre-Mature rupture of membranes & 09 & 4.1 \\
\hline Cord prolapse & 01 & 0.5 \\
\hline Fetal distress & 09 & 4.1 \\
\hline Retention of second twin & 02 & 0.9 \\
\hline Post-Partum haemorrhage. & 09 & 4.1 \\
\hline
\end{tabular}

Table 3: Fetal presentation.

\begin{tabular}{|lll|}
\hline Presentation & No $(\mathrm{n}=217) *$ & $\%$ \\
\hline Cephalic-Cephalic & 95 & 43.8 \\
\hline Cephalic-Breech & 39 & 17.9 \\
\hline Cephalic-Transverse & 03 & 01.4 \\
\hline Breech-Cephalic & 39 & 17.9 \\
\hline Breech-Breech & 29 & 13.4 \\
\hline Breech-Transverse & 03 & 01.4 \\
\hline Transverse-Cephalic & 02 & 0.9 \\
\hline Transverse-Breech & 07 & 03.2 \\
\hline
\end{tabular}

* Out of 218 pairs of twins, in one pair second twin was Fetus

Papyraceous and not considered. Hence $n=217$

Male-male was the commonest sex combination of twin pairs $(30.4 \%)$ in this study. This was followed by femalefemale $(28.6 \%)$ and male-female (24.9\%), Female-male combination was the least common sex combination $(16.1 \%)$ (Table 6). In the present study, there were 208(51.6\%) males and $195(48.4 \%)$ females among the live born twins giving a sex ratio of 938 (Table 7).

Table 4: Mode of delivery.

\begin{tabular}{|lllll|}
\hline Mode of delivery & \multicolumn{2}{c}{ First twin } & \multicolumn{2}{c|}{ Second twin } \\
& $\mathbf{n = 2 1 8}$ & \% & $\mathbf{n = 2 1 8}$ & \% \\
\hline Vaginal delivery & 112 & 51.2 & 110 & 50.5 \\
\hline Caesarean Section & 106 & 48.6 & 108 & 49.5 \\
\hline
\end{tabular}


Table 5: Neonatal outcome

\begin{tabular}{|lllllllll|} 
& \multicolumn{2}{c}{ Still birth } & \multicolumn{2}{c|}{ Live birth } & \multicolumn{2}{c|}{ Low birth weight* } & \multicolumn{2}{c|}{ Low apgar score* } \\
& No. & $\mathbf{\%}$ & No. & \% & No. & \% & No. & \% \\
\hline First Twin (No. 218) & 12 & 5.5 & 206 & 94.4 & 162 & 78.6 & 17 & 8.2 \\
\hline Second Twin (No.217)** & 20 & 9.2 & 197 & 90.3 & 176 & 89.3 & 26 & 13.1 \\
\hline Total 435 & 32 & 7.3 & 403 & 92.6 & 338 & 83.8 & 43 & 10.7 \\
\hline
\end{tabular}

*Data presented for live births **N=217 for second twin as one of the second twins was Fetus Papyraceous and not considered

Table 6: Sex combination of pairs of twins delivered.

\begin{tabular}{|c|c|c|}
\hline Sex combination of twin pairs & No. $*(n=217)$ & $\%$ \\
\hline Male-Male & 66 & 30.4 \\
\hline Female-Female & 62 & 28.6 \\
\hline Male-Female & 54 & 24.9 \\
\hline Female-Male & 35 & 16.1 \\
\hline
\end{tabular}

*Out of 218 pairs of twins, in one pair the second twin was Fetus Papyraceous and not considered. Hence $n=217$

Table 7: Sex of twins delivered.

\begin{tabular}{|llllll|}
\hline Order of twins & \multicolumn{3}{l}{ Sex of twin } & \multicolumn{2}{l|}{ Sex ratio } \\
\hline & Male & \multicolumn{3}{l|}{ Female } & \\
\hline First Twin & 117 & 56.8 & 89 & 43.2 & 761 \\
\hline Second Twin & 91 & 46.2 & 106 & 53.8 & 1165 \\
\hline Total & 208 & 51.6 & 195 & 48.4 & 938 \\
\hline
\end{tabular}

**Data presented for live births

\section{DISCUSSION}

In present study, the incidence of twin pregnancy was found to be 1 in 52 pregnancies or $1.9 \%$ which is similar to that reported by Pandey MR et al in a study from Nepal. ${ }^{11}$ It is comparable to $1.7 \%$ reported by $\mathrm{Ri}-\mathrm{Na}-\mathrm{Su}$ et al, but it is much higher than $1.4 \%$ reported by Basirat et al and 1 in $80(1.2 \%)$ reported by Usta from U.S.A. ${ }^{12-14}$ The high incidence of twin pregnancy in present study may be because of referral of twin pregnancy cases to our institute for better management of complications associated with twin pregnancy and better neonatal care of preterm and low birth weight twins as ours is a tertiary care hospital.

The mean maternal age was 25.4 years which is similar to that reported by Pandey MR et al. ${ }^{11}$ The mean age of women with twin pregnancy was found to be lower by Musilli et al. ${ }^{15}$ Szymusik et al and Rezavand $\mathrm{N}$ et al reported the mean age of women with twin pregnancy to be significantly higher. ${ }^{16,17}$ In a study by Basirat et al, the mean age was not significantly different for single or twin pregnancy. ${ }^{13}$ The discrepancy in the age among different studies may be due to difference in the age of marriage and pregnancy in different regions.

In present study, $52.8 \%$ women with twin pregnancy were multipara. Our finding is consistent with the findings of some other studies which showed higher frequency of twin pregnancy among multipara such as
$66 \%$ by Masuda $\mathrm{S}$ et al Rezavand $\mathrm{N}$ et al, Bangal et al and Blickstein et al observed no difference in parity between singleton and twin pregnancies. ${ }^{17-20}$ Twin pregnancy was found to be associated with lower parity by Musilli et al. ${ }^{15}$ This may be due to differences in genetics and use of Assisted Reproductive Techniques.

In present study $96.3 \%$ Women had spontaneous conception. This is comparable to the finding of Pandey MR. et al who reported spontaneous conception in $97.8 \%$ of women with twin pregnancy. Twin pregnancy after taking ovulation inducing agents was observed in $3.7 \%$ of women in present study compared to $2.2 \%, 8 \%$ and $14 \%$ in studies by Pandey MR et al, Masuda $\mathrm{S}$ et al and Sultana $\mathrm{H}$ et al respectively. ${ }^{11,18,21}$

In present study, $8.2 \%$ of women had family history of twins compared to $4.3 \%, 36 \%$ and $30 \%$ in studies by Pandey MR et al, Masuda $\mathrm{S}$ et al and Sultana $\mathrm{H}$ et al respectively. ${ }^{11,18,21}$

About $74 \%$ cases were unbooked in present study. Pandey MR et al also reported $87.8 \%$ cases were unbooked in their study. ${ }^{11}$ Present finding is contrary to that of Bangal et al who reported that $24 \%$ cases were unbooked. ${ }^{19}$

The incidence of preterm labour leading to preterm delivery was $58.3 \%$ in the present study which is nearer to that reported by other studies $62.5 \%$ by Pandey M.R.et al and $53.8 \%$ by $\mathrm{Ri}-\mathrm{Na} \mathrm{Su}$ et al. ${ }^{11,12}$ It is higher than reported $(44 \%)$ by Sultana $H$. and Chowdhury S. et al and quite lower than reported $(84 \%)$ by Bangal et al. ${ }^{19,21,23}$

In present study the mean gestational age was 35.2 weeks which is similar to the mean gestational age reported by Muzhar et al from Pakistan. ${ }^{24}$ This finding is consistent with those of Ri-Na Su, Basirat, Musilli, Rezavand $\mathrm{N}$ and Szymusik. ${ }^{12,13,15,17,25}$

We found anaemia in $30.7 \%$ cases, hypertension in $17.9 \%$ cases, antepartum haemorrhage in $5.9 \%$ cases, polyhydramnios in $5.5 \%$ cases, premature rupture of membranes and post-partum haemorrhage in $4.1 \%$ cases each. The corresponding figures reported by Bangal et al and Chowdhury et al were $66 \%$ and $35.8 \%$ respectively for anaemia, $18 \%$ and $22.6 \%$ respectively for hypertension, $12 \%$ and $5.75 \%$ respectively for polyhydramnios, $8 \%$ and $5.7 \%$ respectively for 
antepartum haemorrhage, $16 \%$ and $3.8 \%$ respectively for premature rupture of membranes and $18.9 \%$ for postpartum haemorrhage. ${ }^{19,23}$

There was no maternal mortality in this study. Present finding is consistent with the studies conducted by Masuda $\mathrm{S}$ and Sultana $\mathrm{H}$ who did not report any maternal mortality. ${ }^{18,21}$

The present study showed $43.8 \%$ of twin pairs had cephalic-cephalic presentation, $19.3 \%$ cephalic-noncephalic and $36.9 \%$ non-cephalic presentation of first twin. The corresponding figures by Masuda $\mathrm{S}$ et al were $48 \%$ cephalic-cephalic presentation, $16 \%$ cephalic-noncephalic and $36 \%$ non-cephalic first twin. ${ }^{18}$

The rate of caesarean section was $48.6 \%$ for the first twin and $49.5 \%$ for the second twin. The corresponding figures reported by Pandey MR et al were $46 \%$ for the first twin and $48 \%$ for the second twin. ${ }^{11}$ Present finding is comparable to the results reported by other studies such as $56 \%$ (Sultana $\mathrm{H}$ ), $42 \%$ (Obiechina $\mathrm{NJ}$ et al). ${ }^{21,22}$ The higher caesarean section rate in present study was due to malpresentation of first twin, Preterm premature rupture of membranes, antepartum haemorrhage, fetal distress and previous caesarean section. In two cases, caesarean section was done to take out retained second twin.

In present study, more than three fourth $(83.8 \%)$ of live born twins had low birth weight $(<2500$ grams $)$. This finding was consistent with that of Bangal et al who reported $82 \%$ of twins born with low birth weight. ${ }^{19}$ Incidence of low birth weight was higher in present study than reported $(46.6 \%)$ by $\mathrm{Ri}-\mathrm{Na} \mathrm{Su}$ et al from Bejing. ${ }^{12}$ The low birth weight in twin deliveries is due to prematurity and intrauterine growth restriction caused by the pregnancy complications associated with twin pregnancy such as hypertension and anemia.

The mean birth weight of first twin was 2030 grams and that of second twin was 1930 grams in present study. This is nearer to that reported by Pandey MR et al 2100 grams for the first twin and 2040 grams for the second twin. ${ }^{11}$ Kato et al and Preis et al reported that the mean birth weight of twins was significantly lower than that of the neonate born in singleton pregnancy. ${ }^{26,27}$ The incidence of significant discordant growth was $25 \%$ in the present study which is comparable to $28 \%$ reported by Masuda $\mathrm{S}$ et al. ${ }^{18}$ In other studies, it varies from 15 to $29 \%$.

There were 208 (51.6\%) males and 195 (48.4\%) females among live births in present study. Mutihir et al reported $54.7 \%$ of twins to be boys, which was not significantly different from singleton pregnancies. In a study by Rezavand $\mathrm{N}$ et al, $50 \%$ of the twins were males. However, female twins were found to be more frequent by Melamed et al. and Chittacharoen A et al. ${ }^{17,28,29,30}$
In present study, $59 \%$ of twin pairs were of same sex and $41 \%$ were of different sex. More or less similar reports were given by other studies. ${ }^{18}$

The present study is a retrospective study based on the analysis of hospital data of twin deliveries. So, data regarding maternal height, pre-pregnant maternal weight, NICU admission, neonatal morbidity and mortality could not be collected.

\section{CONCLUSION}

Twin pregnancy was found to be associated with adverse maternal and neonatal outcomes. This clearly indicates the need for screening programs for early detection of twin pregnancies, timely referral, better antenatal care and delivery at institution with good neonatal care unit.

\section{Funding: No funding sources}

Conflict of interest: None declared

Ethical approval: The study was approved by the Institutional Ethics Committee

\section{REFERENCES}

1. Bulmer MG, The Biology of Twinning in Man. Oxford: Oxford University Press; 1970.

2. Little J, Thompson B Descriptive epidemiology. In: McGillivray I, Campbell DM, Thompson BJ, editors. Twinning and Twins. New York: Wiley;1988:37-66.

3. Blickstein I, Keith LG multiple pregnancy, epidemiology, gestation and perinatal outcome, $2^{\text {nd }}$ ed. London: Taylor and Francis;2005.

4. Nylander PPS Frequency of multiple births.In: McGillivray I, Nylander PPS, Corney G, editors. Human Multiple Reproduction. London: Saunders; 1975:87-97.

5. Nylander PPS. The phenomenon of twinning. In: Barron SL, Thompson AM, editors. Obstetrical Epidemiology. London: Academic Press;1983:14365

6. Smits J, Monden C. Twinning across the developing World. PLoS ONE. 2011;6(9):e25239.

7. Fauser BC, Devroey P, Macklon NS. Multiple birth resulting from ovarian stimulation for subfertility treatment. Lancet. 2005;365(9473):1807-16.

8. Imaizumi Y. A comparative study of zygotic twinning and triplet rates in eight countries, 19721999. J Biosoc Sci. 2003;35:287-302.

9. Blondel B, Kaminski M. Trends in the occurrence, determinants, and consequences of multiple births. In Seminars Perinatal. 2002;26(4):239-49.

10. Muheree M, Sarojini NB. Assisted reproductive technologies in India. Development. 2006;49:128-34.

11. Pandey MR, Kshetri BJ, Dhakal D. Maternal and Perinatal Outcome in Multifetal Pregnancy: A Study at a Teaching Hospital. Am J Public Health Res. 2015;3(5A):135-8.

12. Su RN, Zhu WW, Wei YM, Wang C, Feng H, Lin L, et al. Maternal and neonatal outcomes in multiple 
pregnancy: a multicentre study in the Beijing population. Chronic Dis Trans Med. 2015;1(4):197202.

13. Basirat Z, Hajiahmadi M. Comparison of maternal and fetal outcomes in twin and single pregnancy. Baol univ J. 1385;8(2):47-50.

14. Usta IM, Nassar AH, Awwad JT, Nakad TI, Khalil AM, Karam KS. Comparison of the perinatal morbidity and mortality of the presenting twin and its co-twin. J Perinatol. 2002;22(5):391-6.

15. Musilli F, Karanja J. Multi fetal pregnancies at a maternity hospital in Nairobi. East Afr Med J. 2009;86(4):162-5.

16. Szymusik I, Jarosz K, Wielgoś M, Krawczyk A, Marianowski L. Comparative analysis of labor in twin pregnancies in years 1997-2001. Ginekol Pol. 2005;76(1):42-8.

17. Rezavand N, Veisi F, Malek-Khosravi S, Zangeneh M, Kohzadi M. Assessment of Frequency of Twin Pregnancy and Neonatal Outcome in Deliveries of Mo'tazedi Hospital, Kermanshah in 2004-2007. J Obstet Gynecol India. 2014;64(1):19-22

18. Masuda S, Sabera K, Rifat A, Parui A, Abu B, Siddique S., Maternal and perinatal outcome of twin pregnancy in a tertiary hospital. Ibrahim Card Med J. 2011:1(2):35-9.

19. Vidyadhar B. Bangal, Shruti M Patel, Devendra N Khairnar Study of maternal and fetal outcome in twin gestation at tertiary care teaching hospital Int $\mathbf{J}$ Biomed Advance Res. 2012;03(10):758-62

20. Blickstein I, Goldman R, Mazkereth R. Incidence and birth weight characteristics of twin born to mothers aged 40 years or more compared with 35-39 years old mothers. J Perinat Med. 2001;29(2):12832.

21. Sultana M, Khatun S, Saha AK, Akhter P, Shah AB. Maternal and perinatal outcome of twin pregnancy in a tertiary hospital. Ibrahim Cardiac Med J. 2011;1(2):35-9.
22. Obiechina NJ, Okolie VE, Eleje GU, Okechukwu ZC, Anemeje OA. Twin versus singleton pregnancies: the incidence, pregnancy complications, and obstetric outcomes in a Nigerian tertiary hospital Int J Womens Health. 2011;3:227-30.

23. Chowdhury S, Hussain MA.Maternal complications in twin pregnancies Mymensingh Med J. 2011;20(1):83-7.

24. Mazhar S, Peerzada A, Mahmud G. Maternal and perinatal complications in multiple versus singleton pregnancies. J Pak Med Assoc. 2002;52(4):143-7.

25. Szymusik I, Jarosz K, Wielgoś M, Krawczyk A, Marianowski L. Comparative analysis of labor in twin pregnancies in years 1987-91 and 1997-2001. Ginekologia Polska. 2005;76(1):42-8.

26. Kato N. Reference birthweight range for multiple birth neonates in Japan. BMC pregnancy and childbirth. 2004;4(1):2.

27. Preis K, Swiatkowska-Freund M, KulikowskaCiecielag K, Gościniak W. The analysis of twin pregnancy and labour in the Department of Obstetrics, Medical Academy, Gdańsk. Ginekologia Polska. 2005;76(3):214-8.

28. Mutihir J, Pam V. Obstetric outcome of twin pregnancies in Jos. Nigeria Niger $\mathrm{J}$ Clin Pract. 2007;10(1):15-8.

29. Melamed N, Yogev Y, Glezerman M. Effect of fetal sex on pregnancy outcome in twin pregnancies. Obstet Gynecol. 2009;114(5):1085-92.

30. Chittacharoen A, Singhakun D, Ayudhya NI. Pregnancy outcome of twin pregnancy in Ramathibodi Hospital. J Med Assoc Thai. 2006;89(4):S76-80.

Cite this article as: Upreti P. Twin pregnancies: incidence and outcomes in a tertiary health centre of Uttarakhand, India. Int J Reprod Contracept Obstet Gynecol 2018;7:3520-5. 